УДК 548.0:534

\title{
Metal Layer Thickness Influence on the Dispersion Characteristics of Acoustic Waves in the Layered Structure "Me/ZnO/Me/diamond"
}

\author{
Sergey I. Burkov* \\ Institute of Engineering Physics and Radio Electronics \\ Siberian Federal University, \\ Svobodny, 79, Krasnoyarsk, 660041 \\ Russia \\ Olga P. Zolotova ${ }^{\dagger}$ \\ Reshetnev Siberian State University of Science and Technology \\ Krasnoyarsky Rabochy, 31, Krasnoyarsk, 660037 \\ Russia \\ Pavel P. Turchin ${ }^{\ddagger}$ \\ Vladimir I. Turchin \\ Institute of Engineering Physics and Radio Electronics \\ Siberian Federal University \\ Svobodny, 79, Krasnoyarsk, 660041 \\ Russia \\ Boris P. Sorokin \\ Technological Institute for Superhard and Novel Carbon Materials \\ 7a Central'naya str., Moscow, Troitsk, 108840 \\ Russia
}

Received 07.10.2017, received in revised form 20.11.2017, accepted 25.12.2017

The research paper presents an analysis of the influence of mass loading represented by two metal layers (the upper and lower electrodes) on variations in the phase velocity of the elastic wave dispersion modes in the piezoelectric layered structure "Me/ZnO/Me/diamond" depending on the frequency and the ratio of the metal layer thickness to the piezoelectric crystalline layer thickness. Aluminum (Al), molybdenum (Mo) and platinum (Pt) are considered as the metal layer materials. It is demonstrated that variation in the elastic wave phase velocity depends on the acoustic impedance of metal layer and its thickness.

Keywords: piezoelectric layered structure, Rayleigh wave, Love wave, mass loading. DOI: $10.17516 / 1997-1397-2018-11-2-206-218$.

\section{Introduction}

Acoustoelectronic devices have finite dimensions and taking into account an elastic wave reflection and refraction from the crystalline plate boundary or two piezoelectric media interface is a topical issue [1]. A more complicated situation develops in multilayered structures, where it

\footnotetext{
*sburkov@sfu-kras.ru

†zolotova@sibsau.ru

${ }^{\ddagger}$ pturchin@sfu-kras.ru

(c) Siberian Federal University. All rights reserved
} 
is also necessary to take into account the interlayer interface, that is, the boundary between two crystalline layers. In this case both, transformation of the elastic vibration type and a surface wave excitation are possible when the bulk wave is reflected from the interlayer interface [2]. At present, a lot of experimental and theoretical studies of various acoustoelectronic devices mass sensitivity have been developed on the basis of multilayered piezoelectric structures operating on transverse and longitudinal thickness modes of elastic vibrations $[2,3]$. In particular, there are studies in which shear vibrations of resonators created on the basis of similar structures were used to create biosensors $[4,5]$. In the sensors based on the resonator with the layered piezoelectric structure, the electrodes thickness is often comparable to the piezoelectric film thickness and, therefore, they cannot be neglected. All the more so that the layers, for example, gold Au or platinum Pt electrodes, which are most often used as a suitable surface for various biochemical applications, have significant values of acoustic impedance [6]. However, studies of mass loading influence in the layered structure do not yet give an answer to the question of the main causes for phase velocity values variations in an elastic wave. Thus, taking into account the influence of the metal layers thickness on dispersion characteristics of an elastic wave in the multilayered piezoelectric structure is of key importance for the design optimization and increasing sensors sensitivity in similar structures $[7,8]$.

The influence of mass loading in the form of metal layers above the piezoelectric layer on the dispersion characteristics of Rayleigh and Love elastic wave modes in piezoelectric layered structures "zinc oxide/diamond" (" $\mathrm{ZnO} /$ diamond") is theoretically studied in the present research paper. These materials have a set of important properties, such as large values of electromechanical coupling coefficient $\mathrm{ZnO}$ and significant values of the volume and surface phase velocities of an acoustic wave in diamond, which are widely used in various acoustoelectronic devices development. Aluminum $(\mathrm{Al})$, molybdenum $(\mathrm{Mo})$ and platinum $(\mathrm{Pt})$ in the form of a sputtered thin film, that are metals that are most often used as electrodes, are considered as the metal layers material $[9,10]$.

\section{Theoretic basis for elastic waves propagation in a layered piezoelectric medium}

Elastic waves of small amplitude propagate in a piezoelectric crystal unperturbed by external influences. The equation of motion, the equation of electrostatics, and the equations of state of the piezoelectric medium have the form of [11]

$$
\begin{gathered}
\rho_{0} \ddot{U}_{A}=\tau_{A B, B}, \quad D_{M, M}=0, \\
\tau_{A B}=c_{A B C D}^{E} \eta_{C D}-e_{M A B} E_{M}, \quad D_{M}=\varepsilon_{M N}^{\eta} E_{N}+e_{M A B} \eta_{A B},
\end{gathered}
$$

where $\rho_{0}$ is crystal density in undeformed state; $U_{A}$ dynamic elastic displacements vector; $\tau_{A B}$ thermodynamic stresses tensor; $D_{M}$ electrical induction vector; $\eta_{C D}$ small deformations tensor; $c_{A B C D}^{E}, e_{M A B}, \varepsilon_{M N}^{\eta}$ elastic, piezoelectric and dielectric constants of the second order. For elastic displacements and electric potential in the form of plane monochromatic waves of small amplitude, the system of equations is written in the form of the well-known Green-Christoffel equation, which must be solved for each layered structure medium used [12].

The considered conditions for an elastic wave propagation in the layered piezostructure in a working orthogonal system of axis, in which $X_{3}$ axis is directed along the outer normal to the layer surface and $X_{1}$ axis coincides with the direction of wave propagation, must satisfy the corresponding boundary conditions. The boundary conditions, in particular, for the four-layered 
structure "metal/piezoelectric/metal/dielectric substrate" (Fig. 1, a) are: the normal components of stress tensor at the metal/vacuum interface are equal to zero; equality of the normal components of a stress tensor at the metal/piezoelectric interface, the equality of displacement vectors and zero wave potential [13]:

$$
\begin{aligned}
& \left.\tau_{3 j}^{(1)}\right|_{x_{3}=d_{1}}=0, \\
& \tau_{3 j}^{(1)}=\left.\tau_{3 j}^{(2)}\right|_{x_{3}=h}, \quad \varphi^{(2)}=\left.0\right|_{x_{3}=h}, \quad \vec{U}^{(1)}=\left.\vec{U}^{(2)}\right|_{x_{3}=h}, \\
& \tau_{3 j}^{(2)}=\left.\tau_{3 j}^{(3)}\right|_{x_{3}=d_{2}}, \quad \varphi^{(2)}=\left.0\right|_{x_{3}=d_{2}}, \quad \vec{U}^{(2)}=\left.\vec{U}^{(3)}\right|_{x_{3}=d_{2}}, \\
& \tau_{3 j}^{(3)}=\left.\tau_{3 j}^{(4)}\right|_{x_{3}=0}, \quad \vec{U}^{(3)}=\left.\vec{U}^{(4)}\right|_{x_{3}=0} .
\end{aligned}
$$

Here $d_{1}, d_{2}$ and $h$ are the thicknesses value of the upper and lower metal layer and piezoelectric layer thickness. In the present paper, it is assumed that $d_{1}=d_{2}$, i.e. metal layers thicknesses are equal. The equality of the boundary conditions determinant matrix (2), which size in this case is $24 \times 24$ to zero, makes it possible to determine elastic wave characteristics.

Substituting elastic wave equations in the form of linear combinations of partial waves into the boundary conditions:

$$
\begin{aligned}
& U_{i}=\sum_{n} C_{n} \alpha_{i}^{(n)} \exp \left[i\left(k_{1} x_{1}+k_{3}^{(n)} x_{3}-\omega t\right)\right], \\
& \varphi=\sum_{n} C_{4} \alpha_{4}^{(n)} \exp \left[i\left(k_{1} x_{1}+k_{3}^{(n)} x_{3}-\omega t\right)\right],
\end{aligned}
$$

where the superscript $n$ corresponds to the number of partial waves in the corresponding crystalline layer. Boundary conditions variations (2) determine all the types of elastic waves propagating in the layered structure. For instance, the first equation in (2) determines the surface Rayleigh wave propagation. The first and last equations describe the elastic wave propagation in a piezoelectric plate. For the considered layered structure $\mathrm{Me} / \mathrm{ZnO} / \mathrm{Me} /$ diamond, the system of boundary condition equations (2) is divided into two independent systems. This is the system of $8 \times 8$ equations for $\mathrm{SH}-$ modes (Love waves) of an elastic wave and the system of $16 \times 16$ equations for Rayleigh modes, which, when used in the layered structure of isotropic metals, the piezoelectric of symmetry group $6 \mathrm{~mm}$ and a dielectric substrate of the cubic crystal will be written as:

$$
\begin{aligned}
& C_{n}^{(1)}\left(C_{11} k_{1} \alpha_{1}^{(n)}+C_{12} k_{3}^{(n)} \alpha_{3}^{(n)}\right) \exp \left[i k_{3}^{(n)} d_{1}\right]=0, \\
& C_{n}^{(1)}\left(k_{1} \alpha_{3}^{(n)}+k_{3}^{(n)} \alpha_{1}^{(n)}\right) \exp \left[i k_{3}^{(n)} d_{1}\right]=0, \\
& C_{n}^{(1)}\left(k_{1} \alpha_{3}^{(n)}+k_{3}^{(n)} \alpha_{1}^{(n)}\right) \exp \left[i k_{3}^{(n)} h\right]- \\
& -C_{n}^{(2)}\left[C_{44}^{(2)}\left(k_{3}^{(n)} \alpha_{1}^{(n)}+k_{1} \alpha_{3}^{(n)}\right)+e_{15} k_{1} \alpha_{4}^{(n)}\right] \exp \left[i k_{3}^{(n)} h\right]=0, \\
& C_{n}^{(1)}\left(C_{11} k_{1} \alpha_{1}^{(n)}+C_{12} k_{3}^{(n)} \alpha_{3}^{(n)}\right) \exp \left[i k_{3}^{(n)} h\right]- \\
& -C_{n}^{(2)}\left[C_{33}^{(2)} k_{3}^{(n)} \alpha_{3}^{(n)}+C_{13}^{(P)} k_{1} \alpha_{3}^{(n)}+e_{33} k_{3}^{(n)} \alpha_{4}^{(n)}\right] \exp \left[i k_{3}^{(n)} h\right]=0, \\
& C_{n}^{(2)}\left[C_{44}^{(2)}\left(k_{3}^{(n)} \alpha_{1}^{(n)}+k_{1} \alpha_{3}^{(n)}\right)+e_{15} k_{1} \alpha_{4}^{(n)}\right] \exp \left[i k_{3}^{(n)} d_{2}\right]- \\
& -C_{n}^{(3)}\left(k_{1} \alpha_{3}^{(n)}+k_{3}^{(n)} \alpha_{1}^{(n)}\right) \exp \left[i k_{3}^{(n)} d_{2}\right]=0, \\
& C_{n}^{(2)}\left[C_{33}^{(2)} k_{3}^{(n)} \alpha_{3}^{(n)}+C_{13}^{(P)} k_{1} \alpha_{3}^{(n)}+e_{33} k_{3}^{(n)} \alpha_{4}^{(n)}\right] \exp \left[i k_{3}^{(n)} d_{2}\right]- \\
& -C_{n}^{(3)}\left(C_{11} k_{1} \alpha_{1}^{(n)}+C_{12} k_{3}^{(n)} \alpha_{3}^{(n)}\right) \exp \left[i k_{3}^{(n)} d_{2}\right]=0
\end{aligned}
$$




$$
\begin{aligned}
& C_{m}^{(1)} \alpha_{i}^{(m)} \exp \left[i k_{3}^{(m)} h\right]-C_{n}^{(2)} \alpha_{i}^{(n)} \exp \left[i k_{3}^{(n)} h\right]=0, \\
& C_{m}^{(3)} \alpha_{i}^{(m)} \exp \left[i k_{3}^{(m)} d_{2}\right]-C_{n}^{(2)} \alpha_{i}^{(n)} \exp \left[i k_{3}^{(n)} d_{2}\right]=0, \\
& C_{n}^{(3)}\left(k_{1} \alpha_{3}^{(n)}+k_{3}^{(n)} \alpha_{1}^{(n)}\right)-C_{n}^{(4)}\left[k_{3}^{(n)} \alpha_{1}^{(n)}+k_{1} \alpha_{3}^{(n)}\right]=0, \\
& \left.C_{n}^{(3)}\left(C_{11} k_{1} \alpha_{1}^{(n)}+C_{12} k_{3}^{(n)} \alpha_{3}^{(n)}\right)-C_{n}^{(4)}\left[C_{11}^{(4)} k_{3}^{(n)} \alpha_{3}^{(n)}+C_{12}^{(4)} k_{1} \alpha_{3}^{(n)}\right)\right]=0, \\
& C_{m}^{(3)} \alpha_{i}^{(m)}-C_{n}^{(4)} \alpha_{i}^{(n)}=0 .
\end{aligned}
$$

Digital superscripts $1-4$ denote layers and a substrate, in accordance with equation (2), $k$ is a wave vector. To calculate the Love waves characteristics in a given structure, the boundary conditions will have the fo

$$
\begin{aligned}
& C_{n}^{(1)} k_{3}^{(n)} \alpha_{2}^{(n)} \exp \left[i k_{3}^{(n)} d_{1}\right]=0 \\
& C_{n}^{(1)} C_{44}^{(1)} k_{3}^{(n)} \alpha_{2}^{(n)} \exp \left[i k_{3}^{(n)} h\right]-C_{n}^{(2)} C_{44}^{(2)} k_{3}^{(m)} \alpha_{2}^{(m)} \exp \left[i k_{3}^{(m)} h\right]=0 \\
& C_{n}^{(2)} C_{44}^{(2)} k_{3}^{(n)} \alpha_{2}^{(n)} \exp \left[i k_{3}^{(n)} d_{2}\right]-C_{n}^{(3)} C_{44}^{(3)} k_{3}^{(m)} \alpha_{2}^{(m)} \exp \left[i k_{3}^{(m)} d_{2}\right]=0 \\
& C_{m}^{(1)} \alpha_{2}^{(m)} \exp \left[i k_{3}^{(m)} h\right]-C_{n}^{(2)} \alpha_{2}^{(n)} \exp \left[i k_{3}^{(n)} h\right]=0 \\
& C_{m}^{(3)} \alpha_{2}^{(m)} \exp \left[i k_{3}^{(m)} d_{2}\right]-C_{n}^{(2)} \alpha_{2}^{(n)} \exp \left[i k_{3}^{(n)} d_{2}\right]=0 \\
& C_{n}^{(3)} C_{44}^{(3)} k_{3}^{(n)} \alpha_{2}^{(n)}-C_{n}^{(4)} C_{44}^{(4)} k_{3}^{(n)} \alpha_{2}^{(n)}=0 \\
& C_{m}^{(3)} \alpha_{2}^{(m)}-C_{n}^{(4)} \alpha_{2}^{(n)}=0
\end{aligned}
$$

\section{Analysis of mass loading influence in a layered structure}

Determination of the multilayered resonator mass sensitivity $(S)$ is mainly used from the energy balance condition as a frequency change, i.e. as a displacement in the relative frequency of the resonator normalized to the surface mass density $[14,15]$

$$
S=\left(\frac{\Delta f}{f_{0}}\right) /\left(f \rho_{s}\right)=\left(\frac{\Delta v}{v}\right) /\left(f \rho_{s}\right),
$$

where $v$ and $f$ are phase velocity and an elastic wave frequency. However, the disadvantage of the equation (6) is that at large values of $f$ frequencies the changes of phase velocity are smoothed in case of increase in the metal layer thickness. Therefore, in the present paper to determine an elastic wave mass sensitivity, the following formula was used:

$$
S_{v}=\frac{\Delta v}{v}=\frac{v-v_{m t}}{v}
$$

where $v_{m t}$ is phase velocity of an elastic wave upon application of a thin metal layer that does not deviate the mechanical boundary conditions. Note that as shown by the computer experiment, this condition is fulfilled at a layer thickness of less than $1 \mathrm{~nm}$. Condition (7), as well, levels the piezoelectric effect influence and, therefore, $S_{v}$ parameter will be independent of the choice of the piezoelectric layer type.

Fig. 1 shows dispersion dependences of phase velocities for the fundamental and first modes of Rayleigh and Love waves on $h \times f$ value (ZnO thickness $\times$ frequency) for the layered structure 
"Me/ZnO/Me/diamond" with the orientation [100] (001) of both the layer and the substrate. Al, Mo and Pt that have different acoustic impedance values $Z=\rho v$, which also make it possible to clarify how the layers with the high and low acoustic impedance of a layer influence phase velocity variations of an elastic wave, respectively, were used as metal layers (Me). The acoustic impedances of the layers used correspond as $Z_{\mathrm{Al}}<Z_{\mathrm{ZnO}}<Z_{\text {diamond }}<Z_{\mathrm{Mo}}<Z_{\mathrm{Pt}}$. The material constants values of the materials used for aluminum and molybdenum (Al, Mo) are taken in [10], $\mathrm{ZnO}$ in [16] and diamond in [17].The isotropic elastic moduli for the polycrystalline platinum were calculated from the experimental values of the elastic constants [18] in accordance with K.S. Aleksandrov's method [19]:

$$
\begin{aligned}
& 3 K=\lambda_{1}, \\
& 2 G=\left(\lambda_{2} \lambda_{3} \lambda_{4} \lambda_{5} \lambda_{6}\right)^{1 / 5},
\end{aligned}
$$

where $K$ and $G$ are the bulk moduli of compression and displacement, $\lambda_{1}$ is the maximum of nondegenerate eigenvalues of the elastic constants symmetrized matrix $\left(3 K=C_{11}+2 C_{12}\right.$, $\left.2 G=C_{11}-C_{12}\right)$ for isotropic media [20].

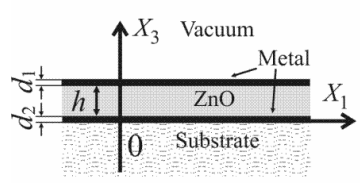

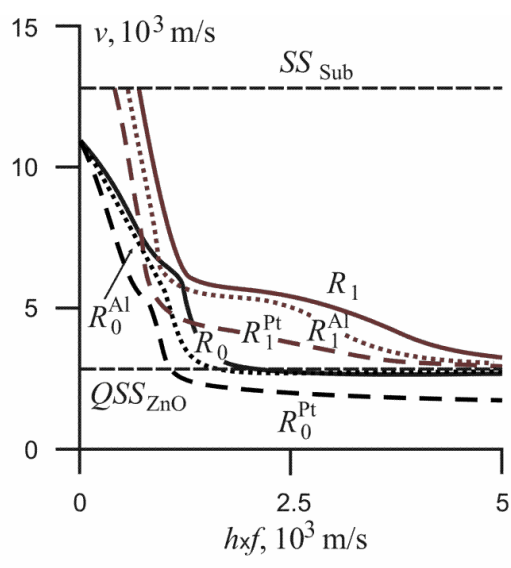

$\mathrm{b}$

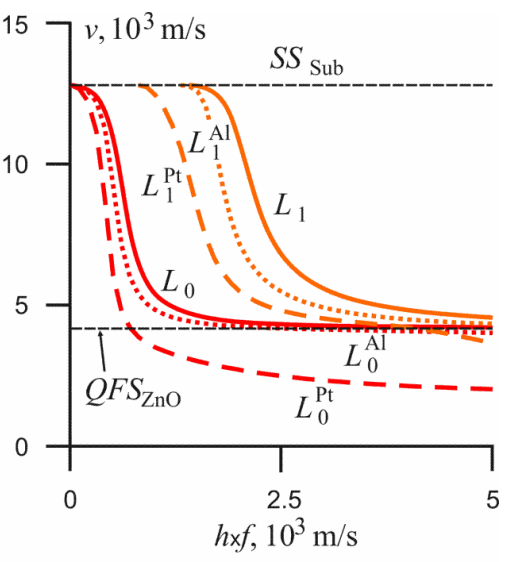

$\mathrm{c}$

Fig. 1. Dispersion dependences of phase velocities on $h \times f$ product for the layered structure "Me/ $\mathrm{ZnO} / \mathrm{Me} /$ diamond": $\mathrm{a}$ - the layered structure scheme, $\mathrm{b}-R_{0}$ and $R_{1}$ modes, c $-S H$ wave $L_{0}$ and $L_{1}$ modes. The solid lines represent the modes velocities for infinitely thin metal layers, the dashed lines represent the velocities for the metal layers thickness $d / h=0.1$

The solid line in Fig. 1 denotes phase velocities for Rayleigh modes of an elastic wave and the modes (SH-modes) of Love wave when the piezoelectric layer is metallized by infinitely thin metal layers that do not violate mechanical boundary conditions. The range of change in phase velocities for the elastic wave modes varies from the value of phase velocity for the diamond shear wave to SAW phase velocity in $\mathrm{ZnO}(v=2730 \mathrm{~m} / \mathrm{s})$ for Rayleigh modes, i.e. amplitude displacement of an elastic wave occurs mainly in the piezoelectric layer. The range of variations in phase velocities for $S H$-modes of an elastic wave also varies from the value of phase velocity for diamond shear wave to phase velocity of a transversely polarized bulk shear wave in $\mathrm{ZnO}$ $(v=4176.2 \mathrm{~m} / \mathrm{s})$.

Calculation of change in the phase velocity modes of an elastic wave was made at the relative ratio of the metal layers thicknesses to the piezoelectric thickness when $d / h=10^{-4} ; 5 \cdot 10^{-4} ; 10^{-3}$; $5 .^{-3} ; 0.005 ; 0.01 ; 0.05 ; 0.1$. The dashed lines in Fig. 1 denote phase velocities of an elastic wave at a relative ratio of the metal layer thickness to the piezoelectric layer $d / h=0.1$. In absolute values, 
the phase velocities values can be represented when piezoelectric layers thickness is $h=10 \mu \mathrm{m}$ and metal layers thickness is $d=1 \mu \mathrm{m}$ in the layered structure "Me/ $\mathrm{ZnO} / \mathrm{Me} /$ diamond" with a frequency change from $1 \mathrm{MHz}$ to $1 \mathrm{GHz}$. The use of metal layers in the layered structure can significantly influence on redistribution of the elastic energy of a wave both as a consequence of the layers acoustic properties and also from the complex interference between the modes of elastic wave that fall and are reflected from the interface between the layers in the structure. In the "Pt/ZnO/Pt/diamond" structure, for instance, as $h \times f$ value increases, the phase velocities of Rayleigh modes of an elastic wave tend to the value of SAW phase velocity in Pt metal layer. However, phase velocities for SH-modes (Love waves) of an elastic wave in the similar case tend to the value of phase velocity of a bulk shear wave in Pt metal. A similar situation occurs when used in a multilayered structure with other metals.

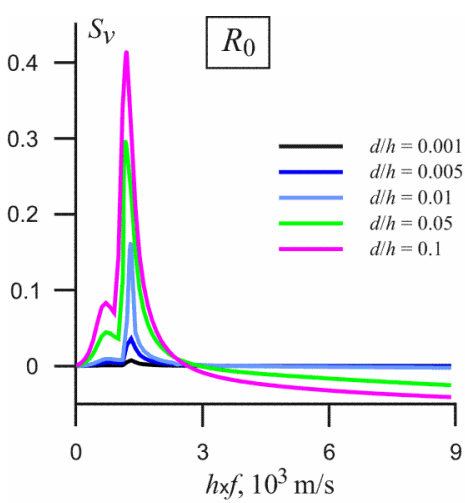

a

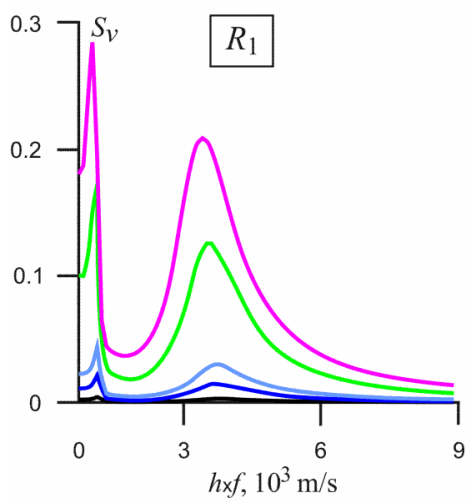

d

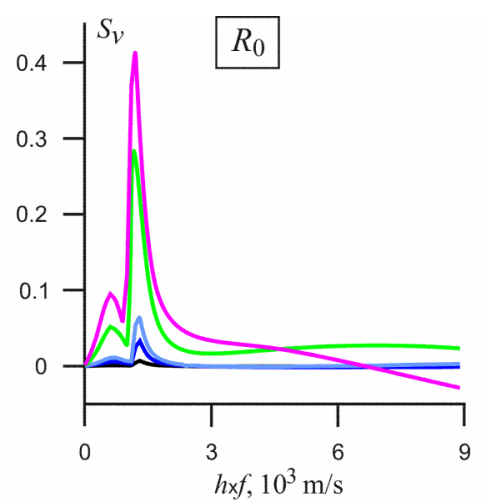

b

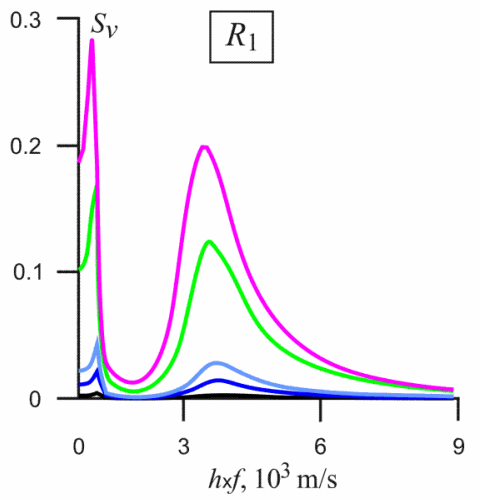

$\mathrm{e}$

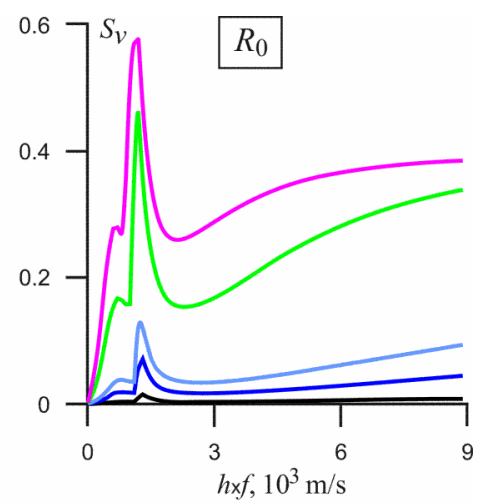

$\mathrm{c}$

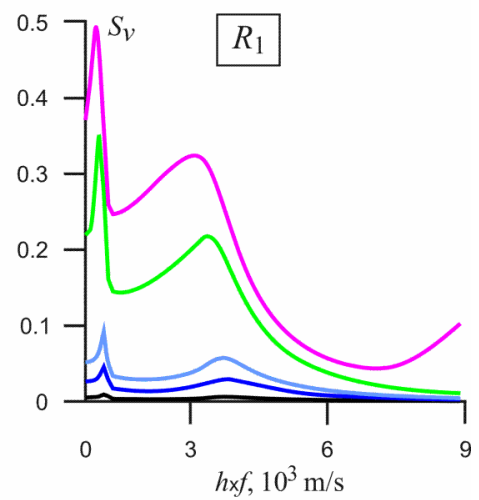

$\mathrm{f}$

Fig. 2. Dispersion dependence of $R_{0}$ and $R_{1}$ modes phase velocities on $h \times f$ product for the layered structure "Me/AlN/Me /diamond": a, d - aluminum, b, e - molybdenum, c, f - gold. Metal thicknesses $d / h: 10^{-3} ; 0.005 ; 0.01 ; 0.05 ; 0.1$

In Fig. 2 the graphs of relative variations in $S_{v}$ phase velocities of the fundamental mode $R_{0}$ and Sezawa wave $\left(R_{1}\right.$ mode), depending on the type of metal layer, $d / h$ ratio and $h \times f$ parameter are represented. The maximum values of $S_{v}$ parameter are attained at a value of $h \times f=1210 \mathrm{~m} / \mathrm{s}$ when all types of metal layers are used, which is determined by the interaction (hybridization) 
between the fundamental $R_{0}$ and the first $R_{1}$ Rayleigh modes of an elastic wave [21]. However, $S_{v}$ parameter values when using $\mathrm{Al}$ or Mo layer are practically identical $S_{v}=0.41$, but for the structure "Pt $/ \mathrm{ZnO} / \mathrm{Pt} /$ diamond" when $h \times f=1210 \mathrm{~m} / \mathrm{s}$ and $d / h$ ratio $=0.1, S_{v}$ parameter $=0.58$. It should be noted that a condition for the "resonant" reflection of the fundamental mode $R_{0}$ of an elastic wave from the layered structure interface at $\lambda / 4$ ( $\lambda$ is the acoustic wave length) also contributes to the variation in $S_{v}$ phase velocity of an elastic wave, which leads to the local maxima appearance in $S_{v}$ values (Fig. 2). There are no similar changes in the values of $S_{v}$ parameter for the first mode of elastic wave $R_{1}$. The maximum values of $S_{v}$ parameter for Sezawa wave (mode $R_{1}$ ) in the interaction region of the acoustic wave modes when using $\mathrm{Al}$ or Mo metal layers are also almost identical $S_{v}=0.28$, but for the structure $\mathrm{Pt} / \mathrm{ZnO} / \mathrm{Pt} /$ diamond" when $h \times f=1110 \mathrm{~m} / \mathrm{s}$ and the ratio of $d / h=0.1 S_{v}$ parameter $=0.48$. The maximum in $S_{v}$ parameter values for the first mode $R_{1}$ is also achieved in the neighborhood of the values $h \times f$ $=3400 \mathrm{~m} / \mathrm{s}$, where the condition $h=\lambda$ is satisfied, i.e. an elastic wave length is equal to a piezoelectric layer thickness (Fig. 2). An increase in the metal layers thickness leads to a slight displacement of the maximum values of $S_{v}$ parameter in the direction of decrease in $h \times f$ value.

The main feature of propagation for the fundamental Rayleigh mode of an elastic wave in the layered structure "Me/ $\mathrm{ZnO} / \mathrm{Me} /$ diamond" is appearance of negative values of $S_{v}$ parameter when using metal layers $\mathrm{Al}$ or $\mathrm{Mo}$, i.e. the value of an elastic wave phase velocity starts increasing when the metal layer is applied (Fig. 2). For the layered structure " $\mathrm{Al} / \mathrm{ZnO} / \mathrm{Al} /$ diamond", this effect is observed for all the metal layer thicknesses under consideration, but is in direct dependence on both the layer thickness and frequency $(h \times f)$. For example, when $d / h$ ratio $=0.01$, negative values of $S_{v}$ parameter appear when $h \times f \geqslant 3700 \mathrm{~m} / \mathrm{s}$, but when $d / h$ ratio $=0.1$ from $h \times f \geqslant$ $2600 \mathrm{~m} / \mathrm{s}$. A different situation arises in the layered structure "Mo/ZnO/Mo/diamond". A slight increase in the phase velocity for the Rayleigh mode of an elastic wave occurs for "thin" metal layers $(d / h \leqslant 0.1)$ and the absolute values of $S_{v}$ parameter $=10^{-4}-10^{-6}$, i.e., the relative change in phase velocity is less than $1 \mathrm{~m} / \mathrm{s}$. However, with the metal layer thickness $d / h=0.1$ and $h \times f$ value $=6150 \mathrm{~m} / \mathrm{s}$, Mo layer thickness becomes equal to a quarter of an elastic wave length $(d=\lambda / 4)$, which leads to resonant reflection and an increase in $S_{v}$ parameter in the negative range of values (Fig. 2, b). It should be noted that in the layered structure "Pt/ZnO/Pt/diamond" there are no negative values of $S_{v}$ parameter due to the high value of elastic wave acoustic impedance.

Fig. 3 shows graphs of the relative change in $S_{v}$ phase velocities of the fundamental mode $\left(S H_{0}\right)$ and the first mode $\left(S H_{1}\right)$ of Love wave, depending on the type of metal layer and the ratio of $d / h$ and $h \times f$ parameter.

The maximum values of $S_{v}$ parameter for $S H_{0}$ mode are reached at $h \times f$ value $=710$ $\mathrm{m} / \mathrm{s}$ when all types of metal layers are used. When using Al or Mo layer, the values of $S_{v}$ parameter $=0.24$ and $S_{v}=0.26$, respectively. But for the structure "Pt $/ \mathrm{ZnO} / \mathrm{Pt} /$ diamond" $S_{v}$ parameter $=0.45$ and $d / h$ ratio $=0.1$. It should be noted that increase in the metal layer thickness leads to the signal frequency displacement when the maximum values of $S_{v}$ parameter are reached. This increase in $S_{v}$ values is particularly significant for the metals with a high acoustic impedance value for the fundamental mode $S H_{0}$ of an elastic wave. However, the numerical $S_{v}$ values differ significantly depending on the type of metal. For instance, in the structure "Al $/ \mathrm{ZnO} / \mathrm{Al} /$ diamond" $S_{v}=0.11$, but in the structure "Pt $/ \mathrm{ZnO} / \mathrm{Pt} /$ diamond" $S_{v}=$ 0.55 when $h \times f=8500 \mathrm{~m} / \mathrm{s}$.

The maximum values of $S_{v}$ parameter for $S H_{1}$ mode of elastic Love wave are attained when $h \times f=2100 \mathrm{~m} / \mathrm{s}$, where the condition of $h=\lambda / 4$ is satisfied, i.e. the piezoelectric layer thickness 


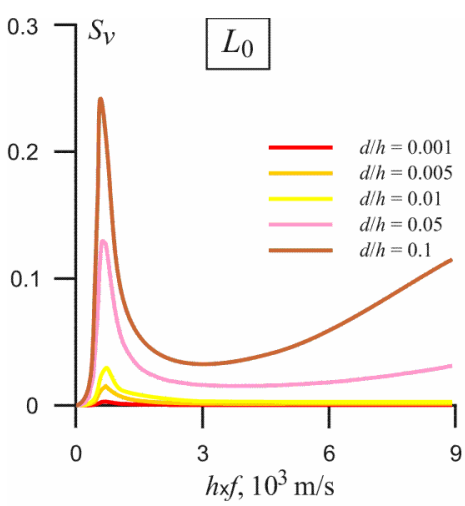

a

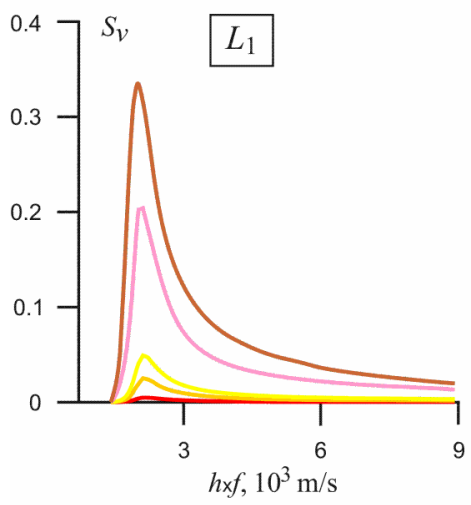

d

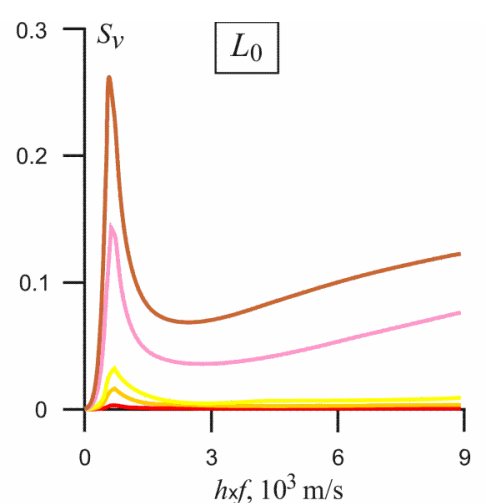

b

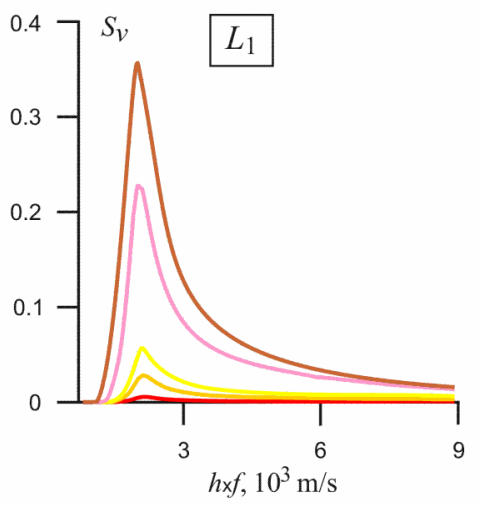

e

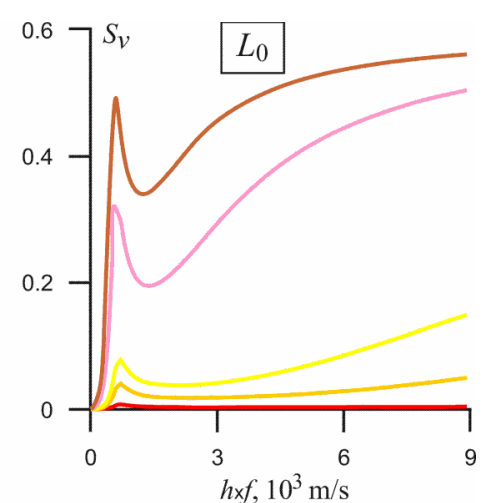

c

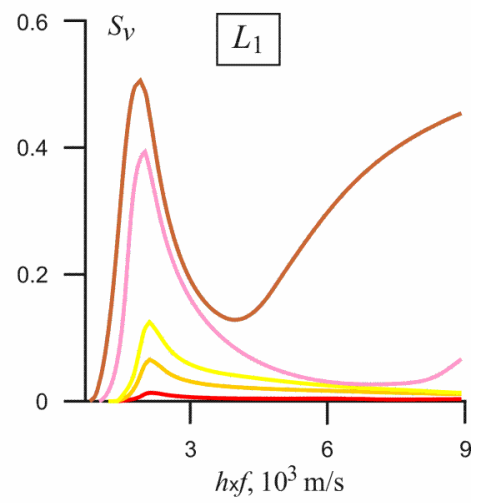

f

Fig. 3. Dispersion dependence of $S H_{0}$ and $S H_{1}$ mode phase velocities variation on $h \times f$ product for the layered structure "Me/AlN/Me/diamond": a, d - aluminum, b, e - molybdenum, c, f — gold. Metal thicknesses $d / h: 10^{-3} ; 0.005 ; 0.01 ; 0.05 ; 0.1$

is equal to a quarter of an elastic wave length (Fig. 3). However, unlike the fundamental $S H_{0}$ mode, for the first $S H_{1}$ mode of Love wave with an increase of $h \times f$ the values of $S_{v}$ parameter decrease with the use of $\mathrm{Al}$ or Mo metal layers. For the structure "Pt/ZnO/Pt/diamond" with a ratio of $d / h>0.05$, the values of the $S_{v}$ parameter increase sharply.

When creating acoustoelectronic devices it is desirable to represent the nature of elastic wave characteristics dependence on the additional layers properties. Fig. 4 shows the dependence of $S_{v}$ parameter on $d / h$ value for the fundamental and the first modes of an elastic wave. For the fundamental Rayleigh mode $R_{0}$ of an elastic wave when using aluminum and molybdenum, the sensitivity dependence of $S_{v}$ on $d / h$ is linear $S_{v}=0.84 \cdot d / h, S_{v}=0.9 \cdot d / h$, respectively. However, when the platinum layer is used, a clearly quadratic dependence is observed: $S_{v}=$ $-11 \cdot(d / h)^{2}+3.9 \cdot d / h$. For Sezawa wave, $R_{1}$ mode of an elastic wave, a similar situation is observed; i.e. also the quadratic dependence of $S_{v}$ parameter on $d / h$ when using the platinum layer is $S_{v}=-25.4 \cdot(d / h)^{2}+5.6 \cdot d / h$ and linear dependence with the use of other metals (Fig. 4). It should be noted that similar dependence can be traced on the entire frequency range considered. However, in the negative values region of $S_{v}$ parameter for the structure 
"Al $/ \mathrm{ZnO} / \mathrm{Al} /$ diamond" the linear dependence $S_{v}=-0.42 \cdot d / h$ is retained, but for the structure "Mo/ZnO/Mo/diamond" it is the clear quadratic dependence $S_{v}=-13.9 \cdot(d / h)^{2}+1.2 \cdot d / h$, when $h \times f=8300 \mathrm{~m} / \mathrm{s}$. In the case of elastic Love waves ( $S H$-wave), a linear dependence is observed only for the structure "Al/ZnO/Al/diamond". For example, for the fundamental $S H_{0}$ mode and the first mode $S H_{1}$ of Love wave, the dependence of $S_{v}$ on $d / h$ value is approximated by the expression $S_{v}=2.2 \cdot d / h, S_{v}=0.94 \cdot d / h$, respectively. However, already for the structure "Mo/ZnO/Mo/diamond" a quadratic dependence $S_{v}=-9.3 \cdot(d / h)^{2}+3.2 \cdot d / h$ is observed for the fundamental mode $S H_{0}$ when $h \times f=710 \mathrm{~m} / \mathrm{s}$ and $S_{v}=-6.4 \cdot(d / h)^{2}+1.6 \cdot d / h$ for $S H_{1}$ mode when $h \times f=3410 \mathrm{~m} / \mathrm{s}$. When using metal layers of platinum, a clearly quadratic dependence presents (Fig. 4). It should be noted that similar dependences of $S_{v}$ parameter are traced on the entire frequency range considered. Thus, in the multilayer structure "Me/ZnO/Me/diamond", the dependence of $S_{v}$ sensitivity is directly dependent on the value of the metal layer acoustic impedance.

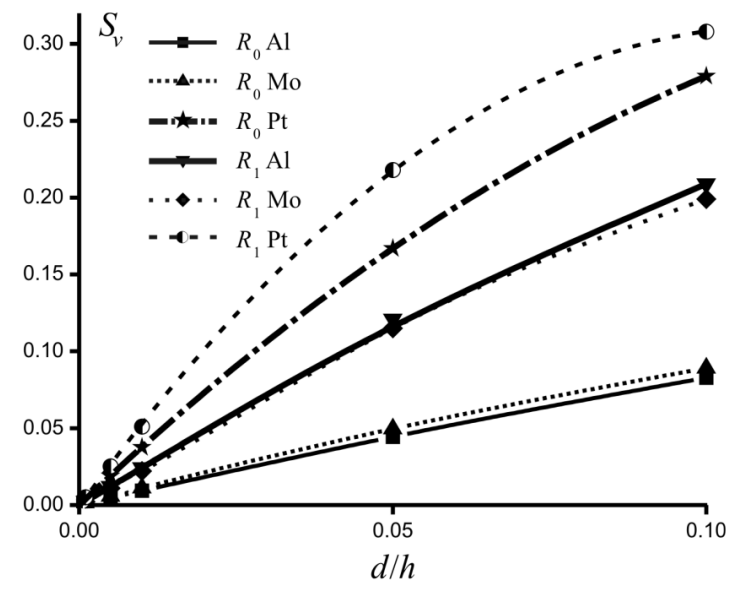

a

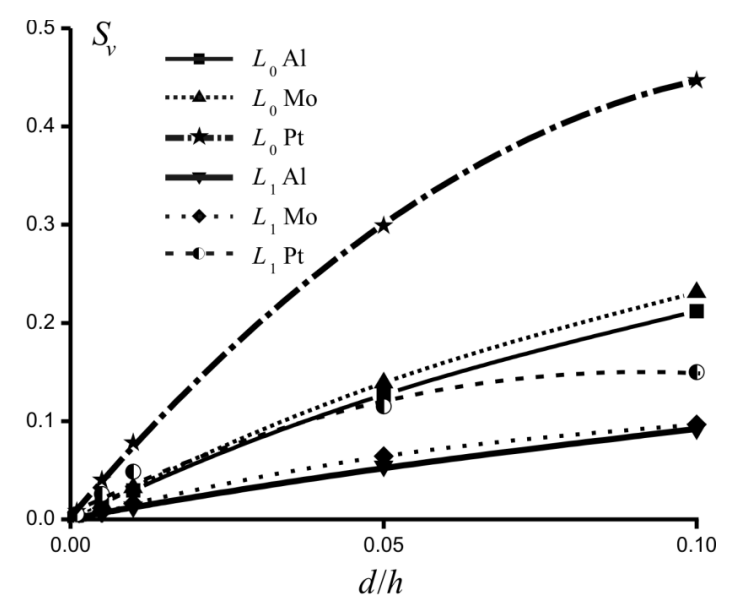

$\mathrm{b}$

Fig. 4. Graphs of $S_{v}$ relationship dependence on the metal thickness, a $-R_{0}$ mode when $h \times f$ $=710 \mathrm{~m} / \mathrm{s}, R_{1}$ mode when $h \times f=3410 \mathrm{~m} / \mathrm{s} ; \mathrm{b}-S H_{0}$ mode when $h \times f=710 \mathrm{~m} / \mathrm{s}, S H_{1}$ mode when $\mathrm{h} \times \mathrm{f}=3410 \mathrm{~m} / \mathrm{s}$

It is important to understand how the upper or lower metal layer affects the phase velocity variations in the piezoelectric structure of "Me/ $\mathrm{ZnO} / \mathrm{Me} /$ diamond" type. For the case of a geometrically asymmetric multilayered structure, when the metal layers thicknesses are different, or the types of electrode materials are different, the values of $S_{v}$ parameter will be different. Fig. 5 shows the dispersion dependences for the fundamental Rayleigh mode $R_{0}$ of an elastic wave in the structures $\mathrm{Me} / \mathrm{ZnO} /$ diamond" and $\mathrm{ZnO} / \mathrm{Me} /$ diamond". In the structure "Me/ZnO/diamond", the character of $S_{v}$ sensitivity behavior for various metals is qualitatively similar to the structure of "Me/ZnO/Me/diamond", it differs mainly numerically. In particular, when $h \times f$ value $=1210 \mathrm{~m} / \mathrm{s}$ and $d / h=0.1, S_{v}$ parameter $=0.14$ for Al and $S_{v}=0.34$ and $S_{v}=0.53$ for Mo and Pt respectively. The character of $S_{v}$ parameter behavior in the structure "ZnO/Me/diamond" differs significantly. First, when using metals Mo and Pt, $S_{v}$ sensitivity values are much less: $S_{v}=0.12$ and $S_{v}=0.2$ respectively, for the same values $h \times f$ values $=1210 \mathrm{~m} / \mathrm{s}$ and $d / h=0.1$. However, when using Al, the situation is opposite, $S_{v}$ sensitivity values increase $S_{v}=0.4$ (Fig. 5). Also, for $h \times f$ values $>5000 \mathrm{~m} / \mathrm{s}, S_{v}$ parameter values are 
less than $10^{-4}$ for all the types of metal layers considered, i.e. the lower metal layer thickness has practically no effect on the phase velocity change in the structure " $\mathrm{ZnO} / \mathrm{Me} /$ diamond".

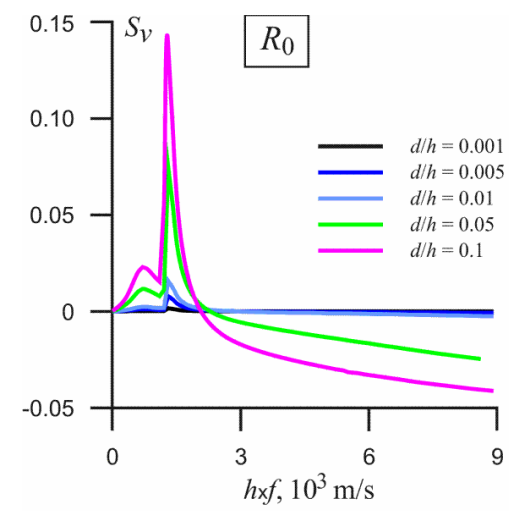

a

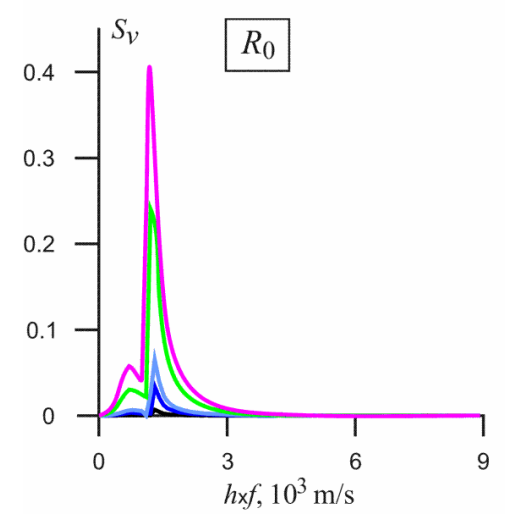

d

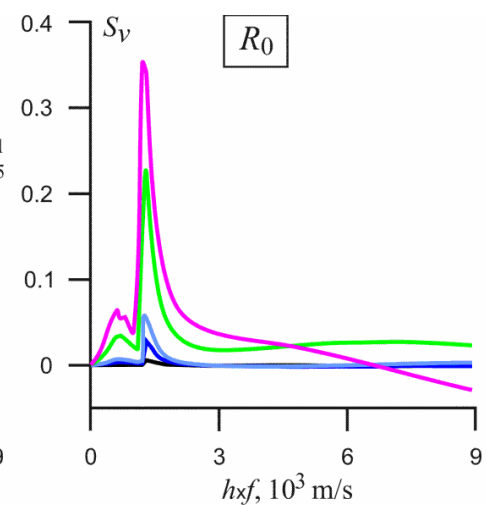

b

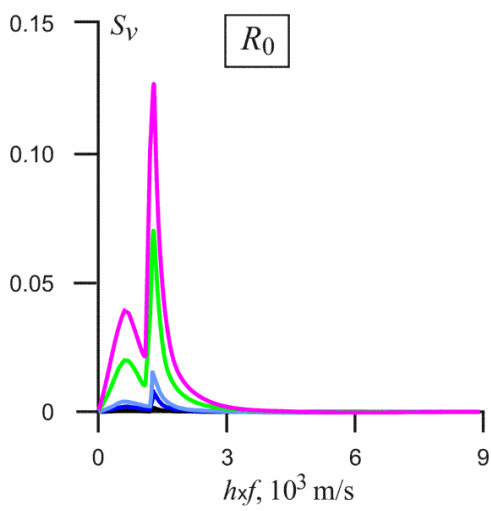

$\mathrm{e}$

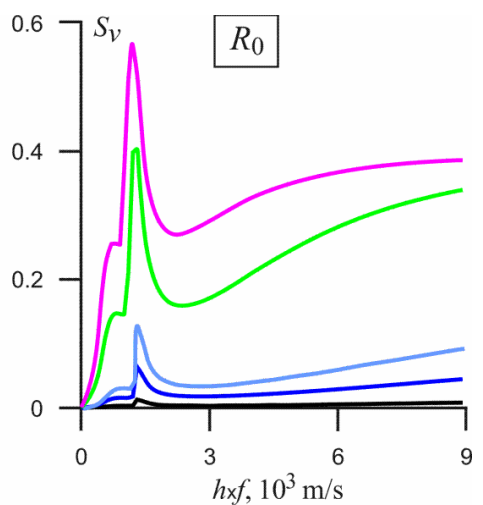

$\mathrm{C}$

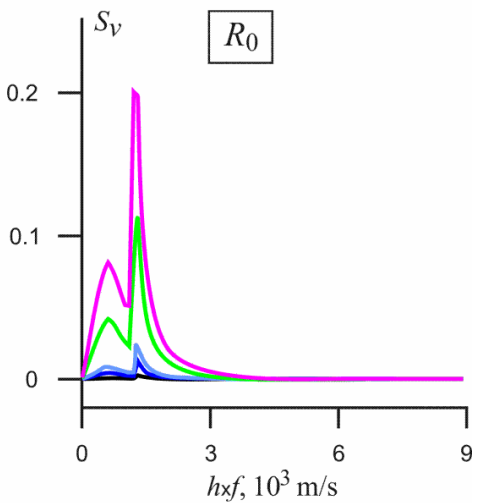

f

Fig. 5. Dispersion dependences of $R_{0}$ mode phase velocity variation on $h \times f$ product for the layered structure "Me/ZnO/diamond" (a-c) and "ZnO/Me/diamond" (d-f): a, d - aluminum, b, $\mathrm{e}-$ molybdenum, c, f-gold. Metal thicknesses $d / h: 10^{-3} ; 0.005 ; 0.01 ; 0.05 ; 0.1$

Fig. 6 shows dispersion dependences of the fundamental mode $S H_{0}$ of Love wave in the structures $\mathrm{Me} / \mathrm{ZnO} /$ diamond" and $\mathrm{ZnO} / \mathrm{Me} /$ diamond". In the structure " $\mathrm{Me} / \mathrm{ZnO} /$ diamond", $S_{v}$ parameter behavior for different metals is also qualitatively similar to the structure "Me/ZnO/Me/diamond". However, especially for the structure "Al/ZnO/diamond", the numerical values of $S_{v}$ parameter differ significantly. In particular, when $h \times f$ value $=710 \mathrm{~m} / \mathrm{s}$ and $d / h=0.1$, the values of $S_{v}$ parameter $=0.08$, but when using Mo metal layer $S_{v}=0.21$. In the structure "ZnO/Me/diamond", the character of $S_{v}$ parameter dispersion behavior for $S H_{0}$ mode differs. If when $\mathrm{Al}$ metal layers are used at $h \times f$ value $=710 \mathrm{~m} / \mathrm{s}$ and $d / h=0.1, S_{v}$ parameter $=0.18$ for $\mathrm{Al}$, but $S_{v}=0.06$ and $S_{v}=0.12$ for Mo and Pt respectively.

Thus, at high values of the metal layer acoustic impedance, the maximum sensitivity values are achieved in case of the upper metal layer presence, i.e. in the structure "Me/ $\mathrm{ZnO} /$ diamond" , but at low acoustic impedance values in the structure " $\mathrm{ZnO} / \mathrm{Me} /$ diamond". 


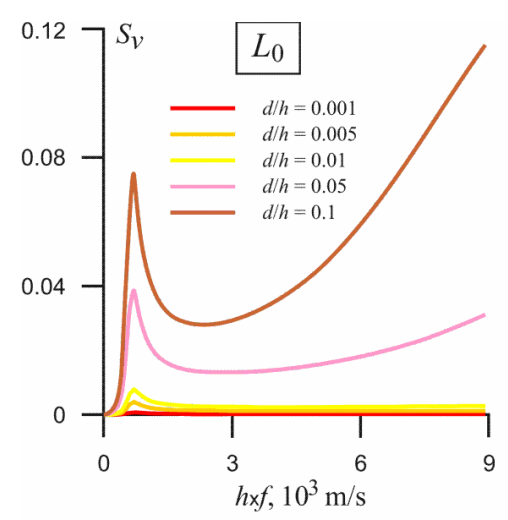

a

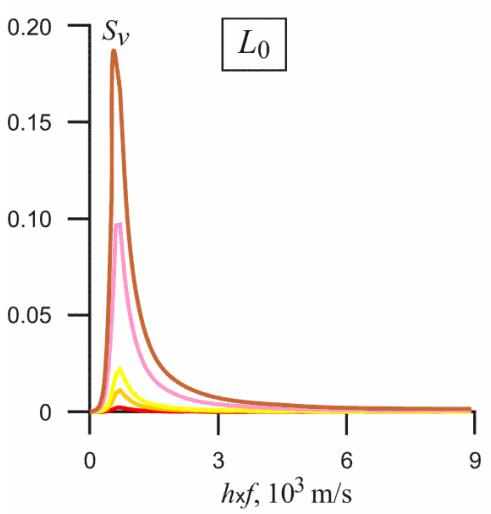

d

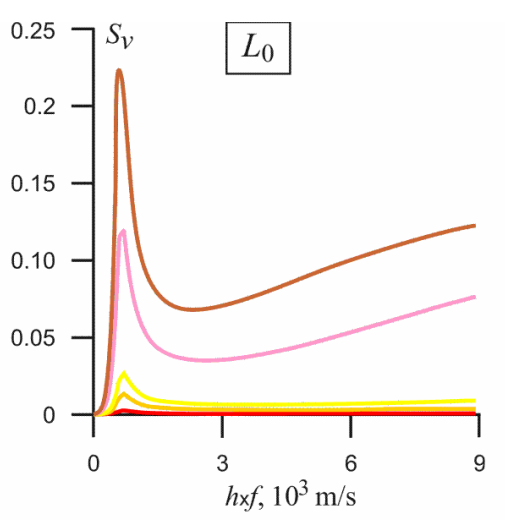

$\mathrm{b}$

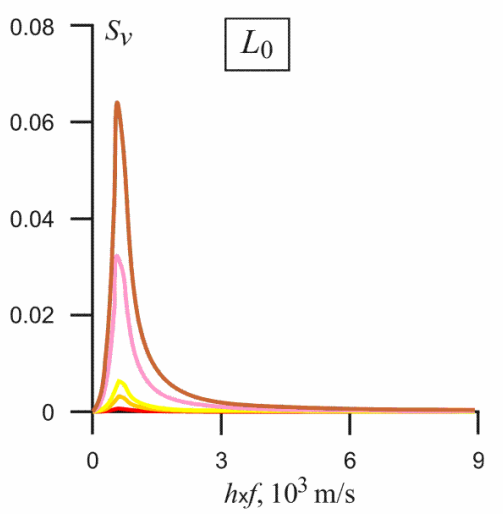

e

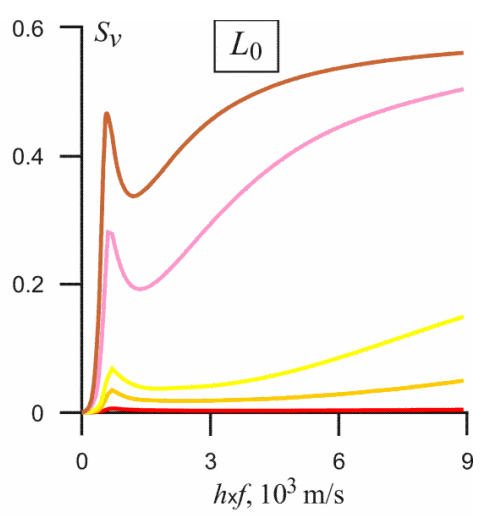

C

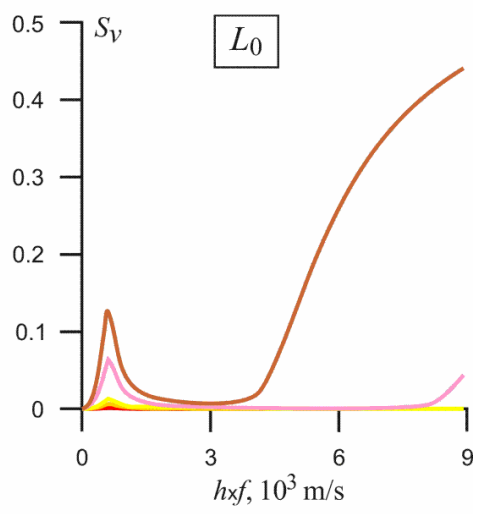

f

Fig. 6. Dispersion dependence of $L_{0}$ mode phase velocity variation on $h \times f$ product for the layered structure "Me/ZnO/diamond" (a-c) and " $\mathrm{ZnO} / \mathrm{Me} /$ diamond" (d-f): a, d - aluminum, b, $\mathrm{e}-$ molybdenum, c, f - gold. Metal thicknesses $d / h: 10^{-3} ; 0.005 ; 0.01 ; 0.05 ; 0.1$

\section{Conclusion}

Influence of mass loading in the form of two metal layers (upper and lower electrodes) on $\Delta v / v$ phase velocity variations of the elastic wave dispersion modes in the piezoelectric layered structure $\mathrm{Me} / \mathrm{ZnO} / \mathrm{Me} /$ diamond is highly correlated to the metal layer acoustic impedance. Note that the maximum values of the phase velocity variations of $\Delta v / v$ elastic wave modes are reached with "Pt/ZnO/Pt/diamond" layer system configuration. The maximum values of $\Delta v / v$ are also reached if the metal layer thickness multiple of a quarter of an elastic wave length. It should be noted that at low values of the metal layer acoustic impedance, more significant variations in $\Delta v / v$ occur due to a change in the lower electrode thickness. However, if the metal layer acoustic impedance is comparable with the substrate acoustic impedance, the increase in $\Delta v / v$ values, in this case, is mostly determined by the upper metal layer thickness.

The results obtained can be useful in the development of the controlled acoustoelectronic devices based on Rayleigh and Love waves.

This work was supported by the Ministry of Education and Science of the Russian Federation (project ID RFMEFI59317X0007; the agreement no. 14.593.21.0007); the work was done 
using the Shared-Use Equipment Center "Research of Nanostructured, Carbon and Superhard Materials" FSBI TISNCM.

\section{References}

[1] S.G.Alekseev, Yu.V.Gulyaev, I.M.Kotelyanskii, G.D.Mansfeld, Some trends in microwave acoustoelectronics development, Physics-Uspekhi, 48(2005), no. 8, 855-859.

[2] H.Zhang, E.S.Kim, Micromachined Acoustic Resonant Mass Sensor, Journal of Microelectromechanical Systems, 14(2005), 699-706.

[3] M.Benetti, D.Cannat, F.Di Pietrantonio, V.Foglietti, E.Verona, Microbalance Chemical Sensor Based on Thin-Film Bulk Acoustic Wave Resonators, Appl. Phys. Let., 87(2005), 173504.

[4] J.Bjurstrom, G.Wingqvist, I.Katardjiev, Synthesis of Textured Thin Piezoelectric AlN Films With a Nonzero C-axis Mean Tilt for the Fabrication of Shear Mode Resonators, IEEE Transactions on Ultrasonics, Ferroelectrics and Frequency Control, 53(2006), 2095-2100.

[5] G.Wingqvist, J.Bjurstom, A.C.Hellgren, I.Katardjiev, Immunosensor Utilizing a Shear Mode Thin Film Bulk Acoustic Sensor, Sensors and Actuators B: Chemical, 127(2007), $248-252$.

[6] T.Nakamoto, T.Moriizumi, A theory of a Quartz Crystal Microbalance Based Upon a Mason Equivalent Circuit, Japanese Journal of Applied Physics, Part 1 (Regular Papers \& Short Notes), 29(1990), 963-969.

[7] B.P.Sorokin, G.M.Kvashnin, A.V.Telichko, G.I.Gordeev, S.I.Burkov, V.D.Blank, Study of High Overtone Bulk Acoustic Resonators Based on the Me1/AlN/Me2/(100) Diamond Piezoelectric Layered Structure, Acoustical Physics, 61(2015), no. 4, 422-433.

[8] B.P.Sorokin, G.M.Kvashnin, A.V.Telichko, A.S.Novoselov, S.I.Burkov, Lamb Waves Dispersion Curves for Diamond Based Piezoelectric Layered Structure, Applied Physics Letters, 108(2016), no. 5, 113501.

[9] Ü.Özgür, Ya.I.Alivov, C.Liu, A.Teke, M.A.Reshchikov, S.Doğan, A V.vrutin, S.-J.Cho, H.Morkoç, A Comprehensive Review of $\mathrm{ZnO}$ Materials and Devices, Journal of Applied Physics, 98(2005), 041301.1992666.

[10] G.D.Mansfeld, S.G.Alekseev, I.M.Kotelyansky, Acoustic HBAR Spectroscopy of Metal (W, Ti, Mo, Al) Thin Films, Proc. Ultras. Symp, IEEE, 2001, 415-418.

[11] G.W.Farnell, Acoustic Surface Waves Topics in Applied Physics, Ed. by A. A. Oliner, 1978.

[12] O.P.Zolotova, S.I.Burkov, B.P.Sorokin, A.V.Telichko, Elastic Waves in Piezoelectric Layered Structures, J. of Sib. Fed. Univ., Math. \& Phys., 5(2012), 164-186.

[13] B.P.Sorokin, G.M.Kvashnin, A.V.Telichko, S.I.Burkov, V.D.Blank, Piezoelectric-Layered Structures Based on Synthetic Diamond, InTech, Piezoelectric Materials, 2016, Ed. Toshio Ogawa, 161-199.

[14] I.E.Kuznetsova, B.D.Zaitsev, S.G.Joshi, A.S.Kuznetsova, Gravimetric Sensitivity of Acoustic Waves in Thin Piezoelectric Plates in the Presence of Liquids, Techn. Phys. Lett., 32(2006), 729-731. 
[15] Wingqvist G., Yantchev V., Katardjiev I. Mass Sensitivity of Multilayer Thin Film Resonant BAW Sensors, Sensors and Actuators A: Physical, 148 (2008), no. 1, 88-95.

[16] Z.Zhang, Z.Wen, C.Wang, Investigation of Surface Acoustic Waves Propagating in ZnO$\mathrm{SiO}_{2}-\mathrm{Si}$ Multilayer Structure, Ultrasonics, 53(2013), no. 2, 363-368.

[17] B.P.Sorokin, G.M.Kvashnin, M.S.Kuznetsov, A.V.Telichko, S.I.Burkov, Experimental Investigation of the Linear and Nonlinear Elastic Properties of Synthetic Diamond Single Crystal, Journal of Siberian Federal University. Math. \& Phys., 1(2013), no. 6, 120-126.

[18] R.E.Macfarlane, J.A.Rayne, C.K.Jones, Anomalous Temperature Dependence of Shear Modulus $_{44}$ for Platinum, Physics Letters, 18(1965), no. 2, 91-92.

[19] K.S.Aleksandrov, P.P.Turchin, G.T.Prodaivoda, Calculation of Elastic Constants of QuasiIsotropic Monomineral Rocks, Izvestiya Physics of The Solid Earth C/C Of Fizika ZemliRossiiskaya Akademiya Nauk, 35(1999), 282-290.

[20] K.S.Aleksandrov, G.T.Prodaivoda, Anisotropy of the Elastic Properties of Minerals and Rocks. Novosibirsk, SB RAS Publishing House, 2000 (in Russian).

[21] I.E.Kuznetsova, Z B.D.aitsev, A.A.Teplykh, I.A.Borodina, Hybridization of Acoustic Waves in Piezoelectric Plates, Acoust. Physics, 53(2007), no. 1, 64-69.

\section{Влияние толщины металлического слоя на дисперсионные характеристики акустических волн в слоистой структуре "Me/ZnO/Me/алмаз"}

Сергей И. Бурков Институт инженерной физики и радиоэлектроники Сибирский федеральный университет Свободный, 79, Красноярск, 660041, Россия

Ольга П. Золотова Сибирский государственный университет науки и технологий имени ак. М. Ф. Решетнёва Красноярский рабочий, 31, Красноярск, 660037, Россия

Павел П. Турчин, Владимир И. Турчин Институт инженерной физики и радиоэлектроники Сибирский федеральный университет Свободный, 79, Красноярск, 660041, Россия

Борис П. Сорокин Технологический институт сверхтвердых и новых углеродных материалов Центральная, 7а, Москва, Троицк, 142190, Россия

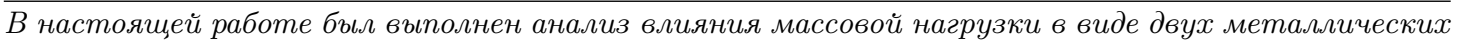
слоев (верхний и нижний электроды) на изменение фазовой скорости дисперсионных мод упругой волны в пъезоэлектрической слоистой структуре "Me/ZnO/Me/алмаз" в зависимости от частоты и отношения толщин металлического слоя $к$ толщине слоя пъезоэлектрического кристалла. В качестве материала металлического слоя рассмотрены алюминий (Al), молибден (Мо) и платина (Pt). Продемонстрировано, что изменение фазовой скорости упругой волны зависит от акустического импеданса металлического слоя и его толщины.

Ключевые слова: пъезоэлектрическая слоистая структура, волна Рэлея, волна Лява, массовая нагрузка. 